\title{
Studies on Positive and Negative ionization mode of ESI-LC-MS/ MS for screening of Phytochemicals on Cassia auriculata (Aavaram Poo)
}

\author{
Paranthaman Ramakrishnan, Sureshkumar Kalakandan*, Muthukumaran Pakkirisamy
}

\section{Paranthaman Ramakrish- nan, Sureshkumar Kalakandan*, Muthuku- maran Pakkirisamy}

(NABL Accredited \& FSSAI Referral lab) Indian Institute of Food Processing Technology (IIFPT), Ministry of Food Processing Industries, Govt. of India, Thanjavur-613 005, Tamil Nadu, INDIA.

Correspondence

\section{Dr. K. Sureshkumar}

Head \& Quality Manager, Department of Food Safety \& Quality Testing \& Food, Biotechnology, (ISO/IEC 17025: 2005 , NABL Accredited lab), Indian Institute of Food Processing Technology, Ministry of Food Processing Industries, Govt. of India, Thanjavur-613 005, Tamil Nadu, INDIA.

Phone No: 91-4362-228155

E-mail: sureshkumar.k@iifpt.edu.in

\section{History}

- Submission Date: 26-09-2017

- Review completed: 03-10-2017;

- Accepted Date: 18-11-2017

DOI : 10.5530/pj.2018.3.75

Article Available online

http://www.phcogj.com/v10/i3

\section{Copyright}

(c) 2018 Phcog.Net. This is an openaccess article distributed under the terms of the Creative Commons Attribution 4.0 International license.

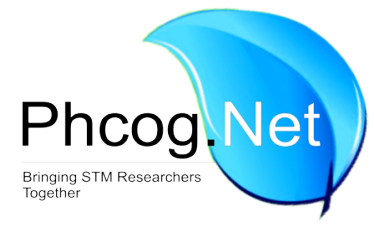

\begin{abstract}
Background: Cassia auriculata (Avaram) is an important medicinal plant in India Improved awareness in medicinal flowers has led to an increased need for efficient extraction methods and screening of flavonoid derivatives. Objective: To standardization of extraction solvent system and Characterization of flavonoids through positive and negative electrospray ionization mode using LC-MS/MS from Cassia auriculata extract. Materials and Methods: The different solvents like Methanol, Water, Acetonitrile, Ethyl Acetate, Ethanol, Chloroform, Hexane, Acetone Diethyl ether used frot he identification of flavonoids (Gallic acid, Theanine, Theobromine, Theophylline, Caffeic acid, Caffeine, Ferulic acid, Theacrine, Catechin, Quercetin, EpiGallo Catachin, catechin gallate, Epicatachin gallate and Quercetin hexoside. Results: Based on the peak area percentage the extraction solvent was standardized. The percentage of relative \& absolute intensity of screened flavonoids was observed using LC-MS in positive and negative electrospray ionization. The results show that the methanol extract has more percentage of peak area, relative intensity and absolute intensity. The MS results showed that the negative ionoization has more intensity values of flavonoids and the signal-to-noise ratio was high in negative ionization mode compare to positive mode. Conclusion: Based on the results the methanol is the suitable extraction solvetnt and negative ionization mode of ESI-LC-MS/MS was appropriate for the screening of flavonoids on Cassia auriculata flower extracts.

Key words: Eelectrospray ionization, Caucalis platycarpos L.; Methanol, Flavonoids; UHPLCESI-MS.
\end{abstract}

\section{INTRODUCTION}

The medicinal plant extracts and phytochemical both with identified antimicrobial properties are of huge importance. A number of studies have been done worldwide to establish antimicrobial behavior from medicinal plants. Cassia auriculata commonly known as" Avaram" that belongs to the Caesalpiniaceous family ${ }^{1}$ and it have great in medicinal properties. The growth of ESI-MS has major impact in phytochemicals and its application has extended to a broad range of flavonoids as well as polar organic, ${ }^{2}$ inorganic ${ }^{3}$ and metal-organic complexes. ${ }^{4}$ The ESI efficiency scale of the different organic molecules with different polarities. ${ }^{5,6}$ The best ESI response has been observed for the analytes with ionizable polar functional groups. In positive ion mode the capillary is the positive electrode (anode) and the sampling aperture plate is the negative electrode (cathode). The positive ions within the eluent solution are repelled from the inner walls of the sprayer needle and move electrophoretically into the body of the droplet formed at the capillary tip. This mode causes positive ions was sprayed droplet and is used where the analytes form cations in solution. In negative ion mode the reverse situation occurs. The capillary is the negative electrode (cathode) and the sampling

aperture plate is the positive electrode (anode). This mode causes negative ions to predominate the sprayed droplet and is used where the analytes form anions in solution. The Flowers of the plant are used in preparation of tea, which is prescribed in diabetes. Compound syrup is prepared with the flowers, mocharas and Indian saparilla which are prescribed for nocturnal emissions. The seeds are used in diabetes, opthalamia and chylous urine. ${ }^{7}$ In the present study an effort has been made to standardization of solvent system (Methanol, Water, Acetonitrile, Ethyl Acetate, Ethanol, Chloroform, Hexane, Acetone Diethyl ether) and Characterization of flavonoids (Gallic acid, Theanine, Theobromine, Theophylline, Caffeic acid, Caffeine, Ferulic acid, Theacrine, Catechin, Quercetin, EpiGallo Catachin, catechin gallate, Epicatachin gallate and Quercetin hexoside) through positive and negative electrospray ionization mode using LC-MS/MS.

\section{MATERIALS AND METHODS}

\section{Sample preparation}

The dried flower was extracted with different solvents such as Methanol, Water, Acetonitrile, Ethyl Acetate,

Cite this article: Paranthaman R, Sureshkumar K and Muthukumaran P. Studies on Positive and Negative ionization mode of ESI-LC-MS/MS for screening of Phytochemicals on Cassia auriculata (Aavaram Poo). Pharmacog J. 2018;10(3):457-62. 
Ethanol, Chloroform, Hexane, Acetone Diethyl ether using Soxhlet $\operatorname{method}^{8}$ for $72 \mathrm{~h}$. The final extract was evaporated to dryness on a rotary vaccum evaporator at $40^{\circ} \mathrm{C}$. The crude extract was re dissolved with 10 $\mathrm{mL}$ methanol and it was purified by solid phase extraction colum.

\section{LCMS analysis of flavonoids}

Flavonoids identification was done as described for LC-MS/MS analysis. ${ }^{9}$ LC Conditions : Column: Inertsil ODS3, $150 \mathrm{~mm} \times 2.1 \mathrm{~mm}, 5 \mu \mathrm{m}$, Mobile phase: $\mathrm{A}=1 \%$ formic acid, B = acetonitrile, Gradient: Start with $5 \% \mathrm{~B}, \mathrm{At}$ $30 \mathrm{~min} 50 \% \mathrm{~B}$, Flow rate: $0.2 \mathrm{~mL} / \mathrm{min}$, Column temperature: $40^{\circ} \mathrm{C}$ and Injection volume: $10 \mu \mathrm{L}$. MS Conditions: Source: ESI,Ion mode: Positive \& Negative , Vcapvoltage: 4000 V, Nebulizer: 50 psig, Drying gas flow: $10 \mathrm{~L} / \mathrm{min}$, Drying gas temp: $350^{\circ} \mathrm{C}$, Corona: $4 \mu \mathrm{A}$, Vaporizer temperature: $350^{\circ} \mathrm{C}$, Scan range: $100-1200 \mathrm{amu}$, Step size: 0.1 , Peak width: $0.15 \mathrm{~min}$ Time filter: On, Fragmentor: $200 \mathrm{~V}$.

\section{RESULTS AND DISCUSSION}

\section{Screening of Flavonoids by HPLC-MS/MS}

The phytochemical fingerprint of Cassia auriculata flower extract was estimated using UHPLC-ESI-MS conditions. The experiments were carried out in order to identification of flavonoids based on the intensity values arrived from LC-MS/MS. The LC-MS Total Ion Chromatogram (TIC) and mass spectrum of positive and negative ionization mode is a shown (Figure 1 to 3 ) by summing up intensities of all flavonoids mass spectral peaks belonging to the full scan.The Positive inonization shows Gallic acid (6.58\%), Theanine (24.69\%), Theobromine (32.1\%), Theophylline (12.76\%), Caffeic acid (59.26\%), Caffeine (13.99\%), Ferulic acid (49.38\%), Theacrine (43.25\%), Catechin (90\%), Quercetin (91.36\%), EpiGallo Catachin (37.45\%), catechin gallate (79.01\%), Epicatachin gallate $(42.39 \%)$ and Quercetin hexoside (6.58\%). The use of UHPLC and minimum sample research accounted for the possibility of this new accurate and fast process for the screening of flavonoids in the extract.

The methanol solvent was most effective in extracting phenolic components from plants. Methanol and ethanol have been proven as effective solvents for extraction of phenolic compounds. ${ }^{10}$ The profile and yield of polyphenol content and antioxidant activity appears higher in more polar solvents. ${ }^{11}$ The Figure 4 to 6 shows that Gallic acid (98.83\%), Theanine (51.99\%), Theobromine (97.15\%), Theophylline (77.93\%), Caffeic acid (90.32\%), Caffeine (72.98\%), Ferulic acid (39.85\%), Theacrine (95.92\%), Catechin (93.93\%), Quercetin (90.36\%), EpiGallo (Catachin83.75\%), catechin gallate (84.08\%), Epicatachin gallate (95.22\%) and Quercetin hexoside (82.14\%) the highest peak area percentage was found in methanol extract on negative ionization and followed by the acetonitrile, ethanol and other solvents. As a result, compared with the extraction yields of phytochemicals by extract solvent for 14 phenolic compounds, it was found that screening of phytochemicals, methanolic extraction for most favorable solvent. The analysis of phenolic acids and their esters were identified and characterized by negative ionization mode. ${ }^{12,13,14}$ The
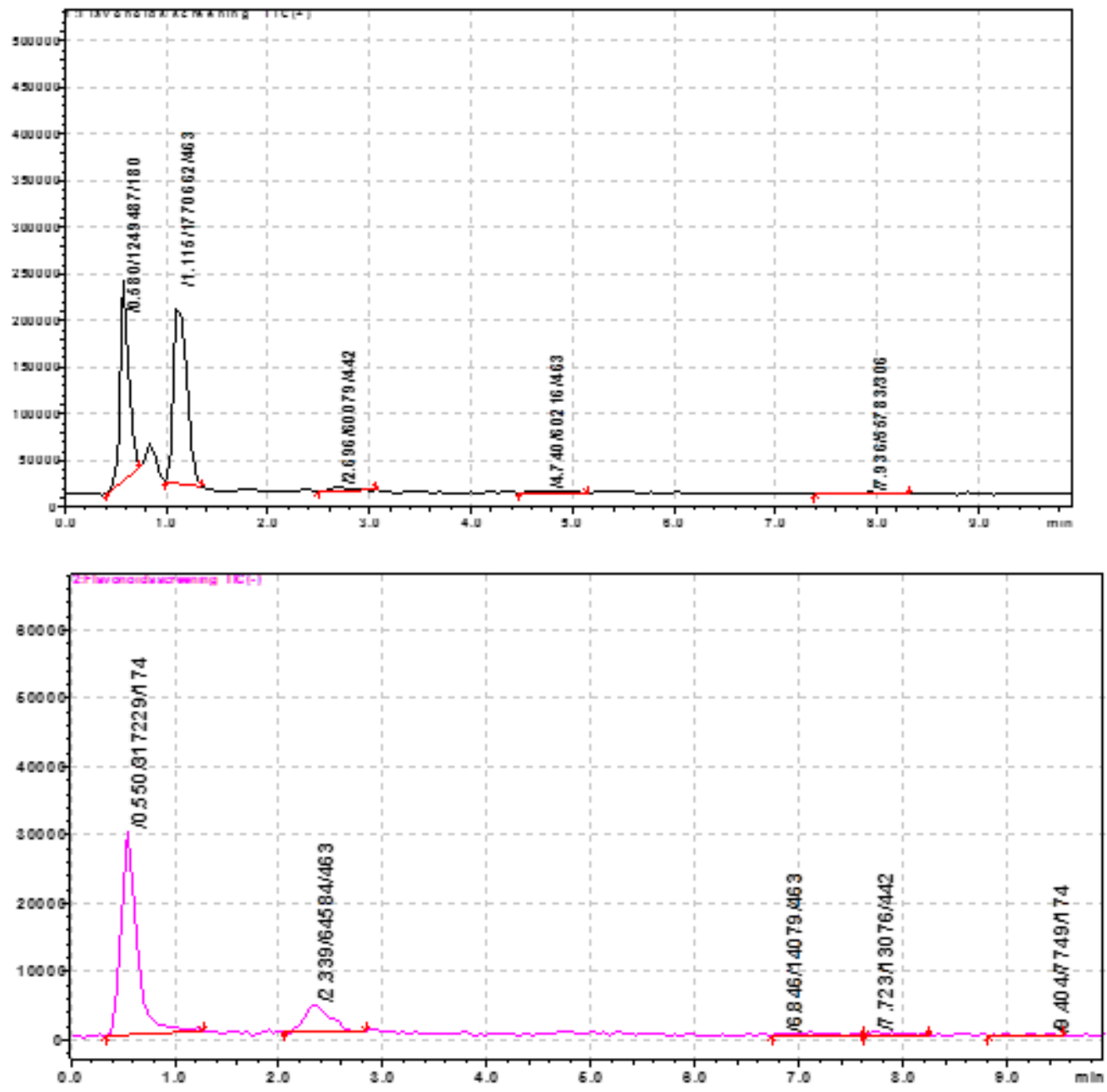

Figure 1: LC-MS Total Ion Chromatogram of flavonoids on Positive \& negative ionization mode 

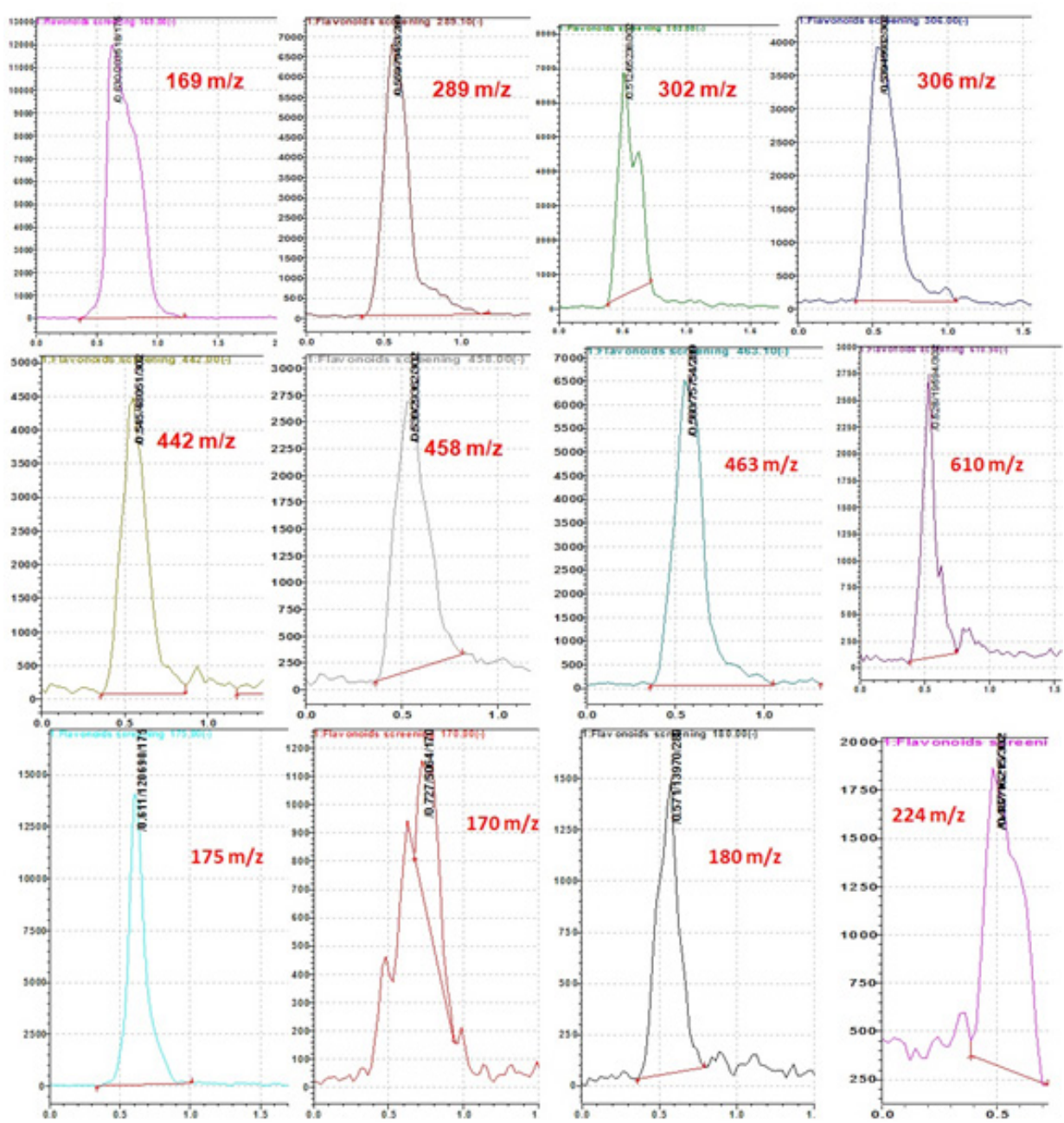

Figure 2: LC-MS Chromatogram of flavonoids on Negative ionization
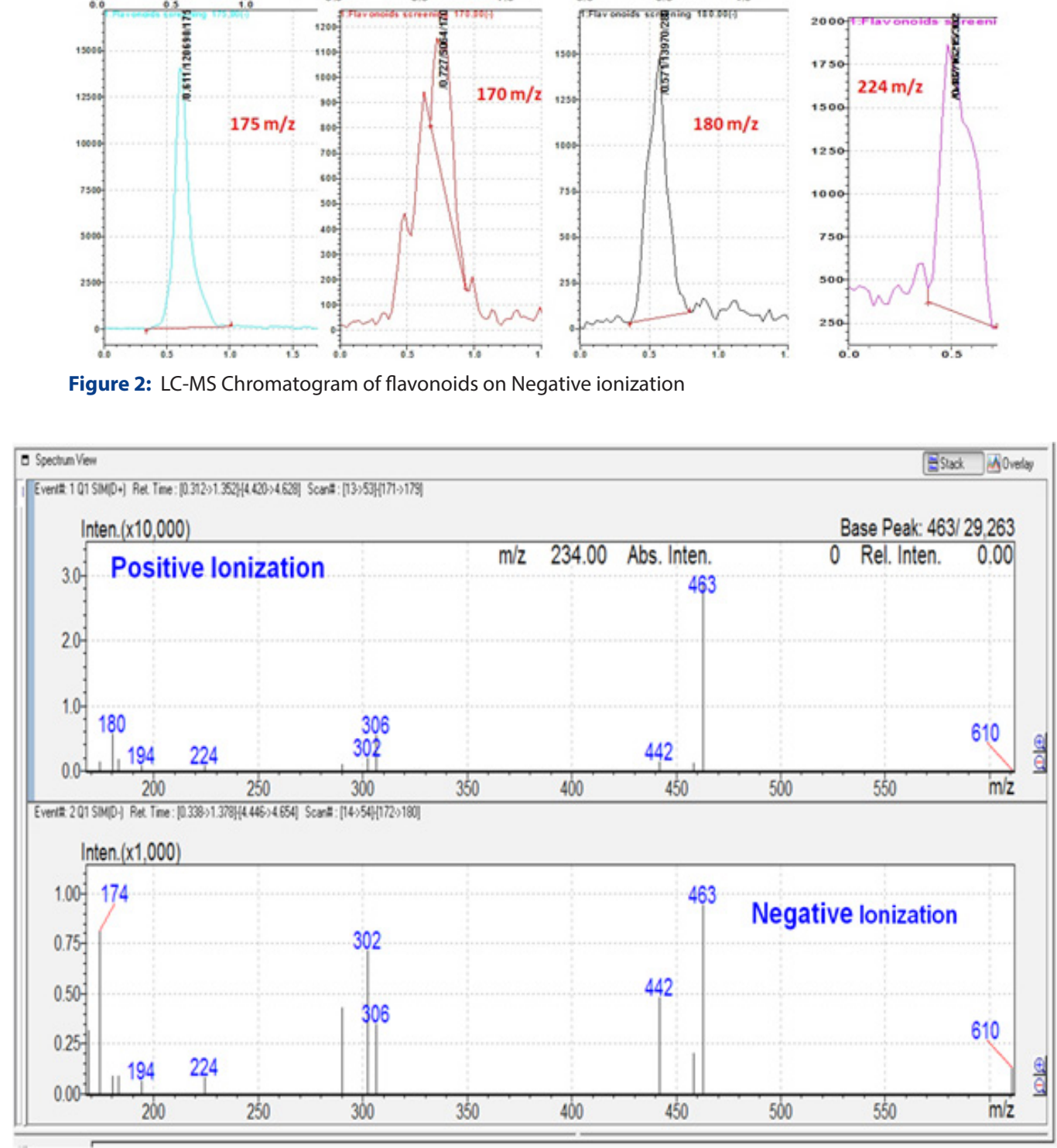

Figure 3: LC-MS mass spectrum of flavonoids on Positive \& negative ionization mode 


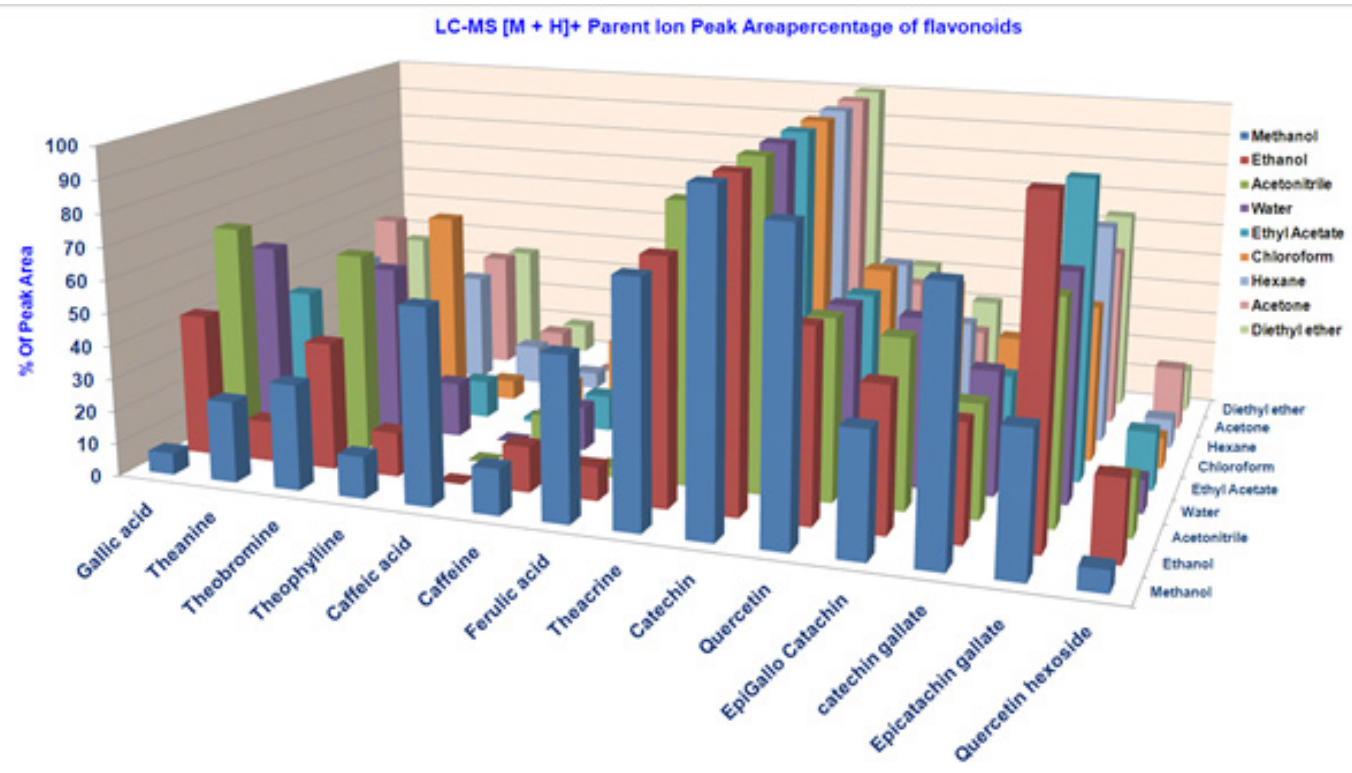

Figure 4: LC-MS $[M+H]+$ (Positive lonization) Parent lon Peak area percentage of flavonoids

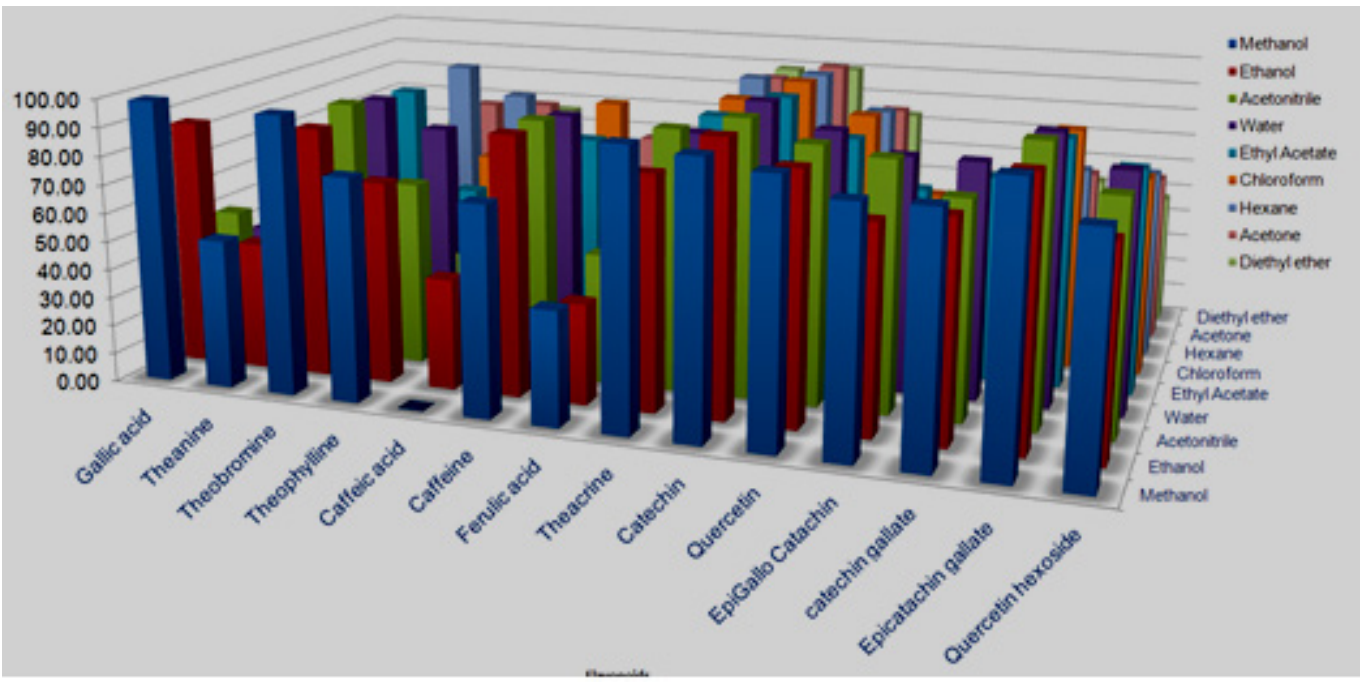

Figure 5: LC-MS [M - H]- (Negative lonization) Parent lon Peak area percentage of flavonoids

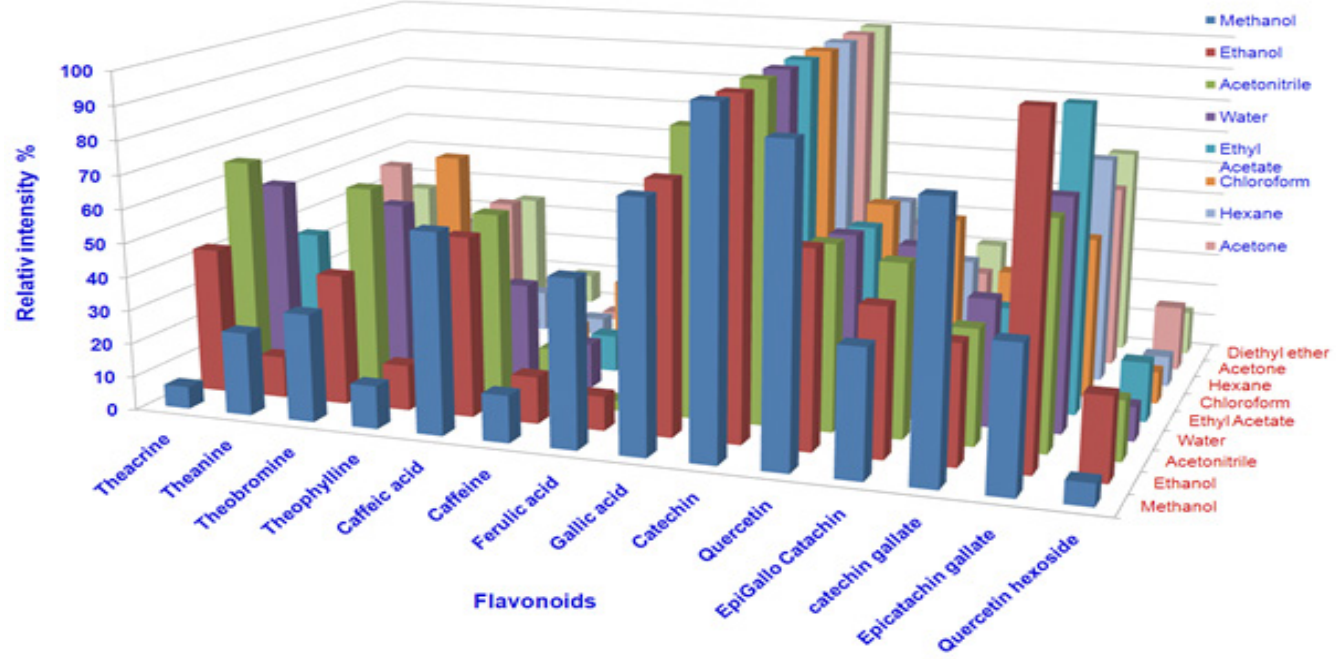

Figure 6: LC-MS [M - H]- (Negative lonization) Parent lon Relative intensity of flavonoids 
Table 1: LC-MS Parameters for Flavonoids screening

\begin{tabular}{cccc}
\hline Analyte & $\mathbf{m} / \mathbf{z}$ & Cone Voltage $(\mathrm{V})$ & Collision energy (eV) \\
\hline Gallic acid & 169 & 15 & -35 \\
Theanine & 170 & 15 & -35 \\
Theobromine & 175 & 15 & -35 \\
Theophylline & 180 & 15 & -35 \\
Caffeic acid & 183.5 & 15 & -35 \\
Caffeine & 194 & 15 & -35 \\
Ferulic acid & 224 & 15 & -35 \\
Theacrine & 289.1 & 15 & -35 \\
Catechin & 302 & 15 & -35 \\
Quercetin & 306 & 15 & -35 \\
EpiGallo Catachin & 442 & 15 & -35 \\
catechin gallate & 458 & 15 & -35 \\
Epicatachin gallate & 463.1 & 15 & -35 \\
Quercetin hexoside & 610.5 & 15 & \\
\hline
\end{tabular}

Table 2: LC-MS data of flavonoids on Positive \& negative ionization mode

\begin{tabular}{ccccccc}
\hline \multirow{2}{*}{$\mathbf{m} / \mathbf{z}$} & \multirow{2}{*}{$\begin{array}{c}\text { Retention } \\
\text { Time (Rt) }\end{array}$} & \multicolumn{2}{c}{ Absolute Intensity } & \multicolumn{2}{c}{ Relative Intensity } & \multirow{2}{*}{ Compound } \\
\cline { 5 - 6 } & Positive & Negative & Positive & Negative & \\
169 & 0.63 & 604 & 227 & 0.78 & 26.49 & Gallic acid \\
170 & 0.727 & 2014 & 1545 & 5.28 & 88.33 & Theanine \\
175 & 0.611 & 194 & 5867 & 20.05 & 8.51 & Theobromine \\
180 & 0.571 & 224 & 2025 & 6.92 & 9.82 & Theophylline \\
183.5 & 0.561 & 174 & 910 & 3.11 & 7.63 & Caffeic acid \\
194 & 0.534 & 148 & 941 & 3.22 & 6.49 & Caffeine \\
224 & 0.487 & 221 & 1065 & 3.64 & 9.69 & Ferulic acid \\
289.1 & 0.559 & 1081 & 1150 & 3.93 & 47.41 & Theacrine \\
302 & 0.512 & 1839 & 2165 & 7.4 & 80.66 & Catechin \\
306 & 0.539 & 849 & 5619 & 19.2 & 37.24 & Quercetin \\
442 & 0.545 & 1030 & 1616 & 5.52 & 45.18 & EpiGallo Catachin \\
458 & 0.539 & 446 & 1322 & 4.52 & 19.56 & catechin gallate \\
463.1 & 0.560 & 2280 & 29263 & 100 & 100 & Epicatachin gallate \\
610.5 & 0.528 & 328 & 264 & 0.9 & 14.39 & Quercetin hexoside \\
\hline
\end{tabular}

recovery of phenolic contents in different samples is influenced by the polarity of extracting solvents and the solubility of each compound in the solvent used for the extraction process. ${ }^{15,16}$ High-performance liquid chromatography has been coupled with the ESI-MS for the molecular fractionation prior to mass-spectrometric analysis. Thus, HPLC/ESI-MS has efficient method competent of analyzing both small and large molecules of various polarities in a plant extract.

\section{CONCLUSION}

UHPLC-ESI-MS/MS in the Negative ionization mode enables the state screening of phytochemicals from Cassia auriculata flower extract using methanol. Liquid mass spectrometry served indeed a potent analytical instrument from qualitative and point of view for all types of phytochemicals investigated. By studying the methanolic Cassia auriculata flower extract, it was proved that the Eelectrospray ionization mass spectrometry (MS) based Qualitative analysis of phytochemicals is agreeable method in negative ionization of Single Ion Monitoring mode (Q1 SIM).

\section{ACKNOWLEDGEMENT}

The authors would like to special thank Dr. C. Anandharamakrishnan, M.Tech, PhD (UK), FIE, FRSC, DIRECTOR , Indian Institute of Food Processing Technology (IIFPT), Ministry of Food Processing Industries, 
Govt.of.India, Thanjavur-613 005 TamilNadu, for their support of this study.

\section{CONFLICT OF INTEREST}

We have a competing interest to declare and authors have no conflict of interest to declare.

\section{ABBREVIATION USED}

UHPLC: ULTRA High Performance Liquid Chromatography; ESI: Electron Spray Ionization; MS: MASS Spectrophotometer; SIM: Single Ion Monitoring mode; Q1: Quadrupole 1.

\section{REFERENCES}

1. Thulasi G. and Amsaveni V. Antibacterial Activity of Cassia auriculata Against ESBL Producing E. coli from UTI Patients: International Journal of Microbiological Research. 2012;3(1):24-9.

2. Wilson SR, Wu Y. Applications of electrospray ionization mass spectrometry to neutral organic molecules including fullerenes. Journal of the American Society for Mass Spectrometry. 1993;4(7):596-603.

3. Hop CE, Bakhtiar R. Electrospray ionization mass spectrometry. Part III: applications in inorganic chemistry and synthetic polymer chemistry. Journal of Chemical Education. 1996;73(8):A162-A9,

4. Keith-Roach MJ. A review of recent trends in electrospray ionisation-mass spectrometry for the analysis of metal-organic ligand complexes. Analytica Chimica Acta. 2010;678(2):140-8.

5. Leito I, Herodes K, Huopolainen Met al. Towards the electrospray ionization mass spectrometry ionization efficiency scale of organic compounds. Rapid
Communications in Mass Spectrometry. 2008;22(3):379-84.

6. Oss M, Kruve A, Herodes K, Leito I. Electrospray ionization efficiency scale of organic compound. Analytical Chemistry. 2010;82(7):2865-72.

7. Doshi GM, Supriya S. Gayatri SV. Preeja PA. Abhijeet PB. Desai SK. Antibacterial potential of Cassia auriculata flowers, J. Microbiol. Biotech. Res. 2011;1(3):15-9.

8. Nihal Dogruoz, Zuhal Zeybek, Ali Karagoz. Antibacterial activity of some plant extracts; Istanbul University, Faculty of Science Journal of Biology. 2008:67(1):17-22.

9. Podolak I, Olech M, Galanty A, Załuski D, Grabowska K, Sobolewska DM. et al. Flavonoid and phenolic acid profile by LC-MS/MS and biological activity of crude extracts from Chenopodium hybridum. Natural Product Research. 2016;30(15):1766-70. doi: 10.1080/14786419.2015.1136908.

10. Sun T, Ho C. Antioxidant activities of bucke wheat extracts. Food Chem 2005;90(4):743-9

11. Chudnoff M: Tropical Timber of the World. USDA Forest Service. Ag. Handbook, No 6071984.

12. Pandey R, Kumar B. HPLC-OTOF-MS/MS-based rapid screening of phenolics and triterpenic acids in leaf extracts of Ocimum species and their interspecies variation, Journal of Liquid Chromatography and Related Technologies. 2016;39(4):225-38, DOI: 10.1080/10826076.2016.1148048

13. Huang L, Chen T, Ye Z, Chen G. Use of Liquid Chromatography- Atmospheric Pressure Chemical Ionization-ion Trap Mass Spectrometry for Identification of Oleanolic Acid and Ursolic Acid in Anoectochilus roxburghii(wall.) Lindl. J. Mass Spectrom. 2007;42(7):910-7.

14. Fang N, Yu S, Prior DL. LC/MS/MS Characterization of Phenolic Constituents in Dried Plums. J. Agric. Food Chem. 2002;50(12):3579-85.

15. Alothman M, Bhat R, Karim A. Antioxidant capacity and phenolic content of selected tropical fruits from Malaysia, extracted with different solvents. Food Chem. 2009;115(3):785-8

16. Sulaiman S, Sajak A, Supriatno K, Seow E. Effect of solvents in extracting polyphenols and antioxidants of selected raw vegetables. Food comp anal. 2011;24(4):506-15.

\section{GRAPHICAL ABSTRACT}

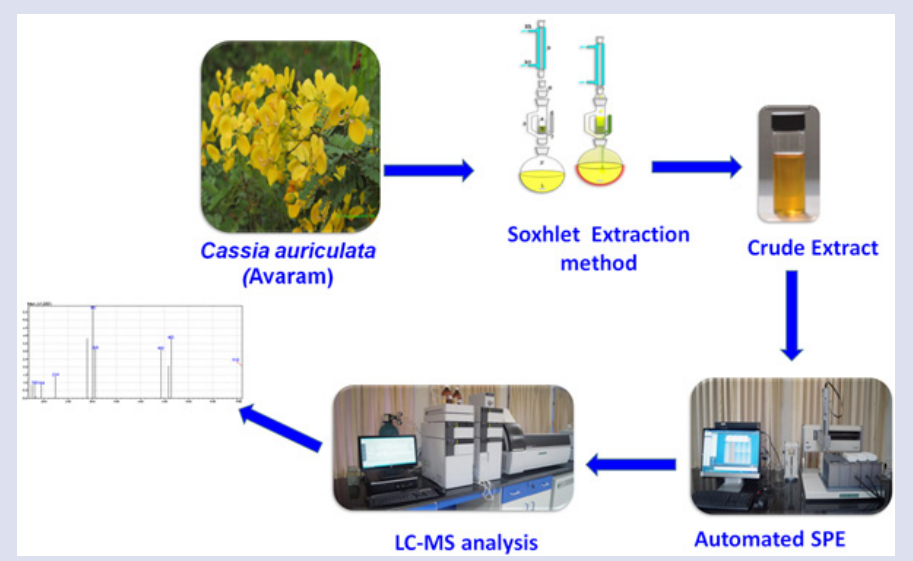

\section{SUMMARY}

- The present work has been performed to extensive qualitative study on the bioactive components of Cassia auriculata flower extract using UHPLC-ESIMS/MS. The positive and negative electrospray ionization mode was optimized and negative ionization was suitable for the determination of flavonoids like Gallic acid,Theanine, Theobromine, Theophylline, Caffeic acid, Caffeine, Ferulic acid, Theacrine, Catechin, Quercetin, EpiGallo Catachin, catechin gallate, Epicatachin gallate and Quercetin hexoside on methanol extract.

\section{ABOUT AUTHORS}

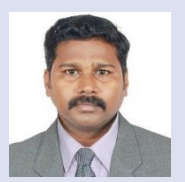

Shri.R.Paranthaman: Technical Officer (Laboratory), Department of Food Safety and Quality Testing, Indian Institute of Food Processing Technology, Thanjavur, Tamil Nadu, India.

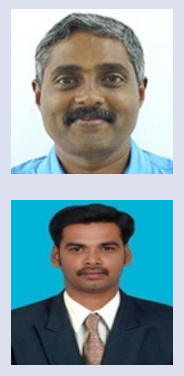

Dr. K.Suresh Kumar: Associate Professor and Head i/c of Department of Food Safety and Quality Testing, Indian Institute of Food Processing Technology, Thanjavur, Tamil Nadu, India.

Dr.P.Muthukumaran: Senior Research Fellow, Department of Food Safety and Quality Testing, Indian Institute of Food Processing Technology, Thanjavur, Tamil Nadu, India.

Cite this article: Paranthaman R, Sureshkumar K and Muthukumaran P. Studies on Positive and Negative ionization mode of ESI-LCMS/MS for screening of Phytochemicals on Cassia auriculata (Aavaram Poo). Pharmacog J. 2018;10(3):457-62. 